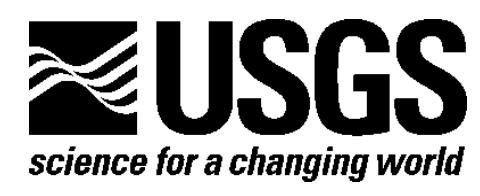

Prepared in Cooperation with the U.S. Environmental Protection Agency

\title{
Research Implementation and Quality Assurance Project Plan: An Evaluation of Hyperspectral Remote Sensing Technologies for the Detection of Fugitive Contamination at Selected Superfund Hazardous Waste Sites
}

By E. Terrence Slonecker and Gary B. Fisher

Open-File Report 2009-1048 


\section{U.S. Department of the Interior \\ KEN SALAZAR, Secretary}

\section{U.S. Geological Survey \\ Suzette M. Kimball, Acting Director}

U.S. Geological Survey, Reston, Virginia: 2008

For product and ordering information:

World Wide Web: http://www.usgs.gov/pubprod

Telephone: 1-888-ASK-USGS

For more information on the USGS-the Federal source for science about the Earth,

its natural and living resources, natural hazards, and the environment:

World Wide Web: http://www.usgs.gov

Telephone: 1-888-ASK-USGS

Suggested citation:

Slonecker, E.T., and Fisher, G.B., 2009, Research Implementation and Quality Assurance Project Plan—An evaluation of hyperspectral remote sensing technologies for the detection of fugitive contamination at selected Superfund sites: U.S. Geological Survey Open-File Report 2009-1048, 18 p.

Any use of trade, product, or firm names is for descriptive purposes only and does not imply endorsement by the U.S. Government.

Although this report is in the public domain, permission must be secured from the individual copyright owners to reproduce any copyrighted materials contained within this report. 


\section{Contents}

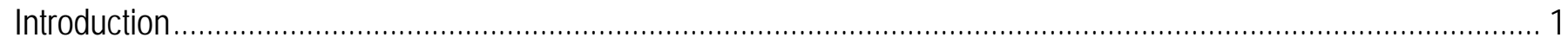

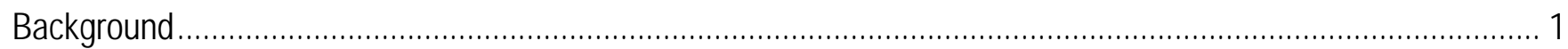

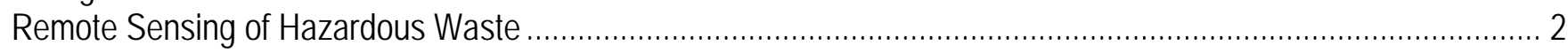

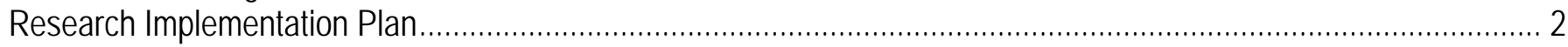

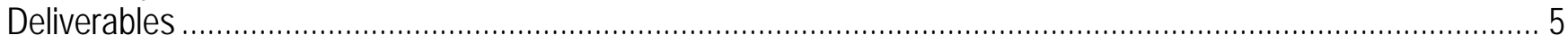

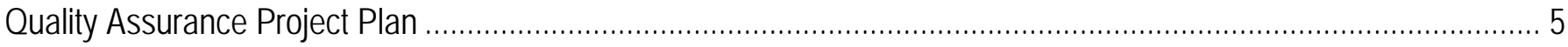

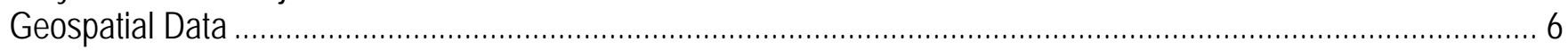

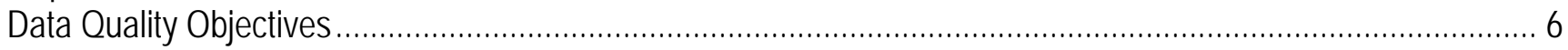

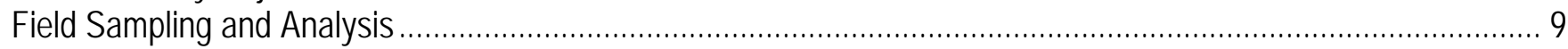

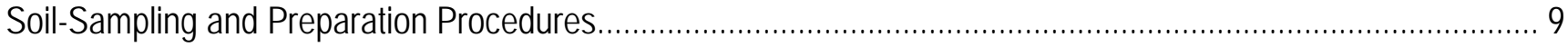

Vegetation-Sampling and Preparation Procedures ................................................................................. 9

Sediment Sampling and Preparation Procedures.................................................................................10

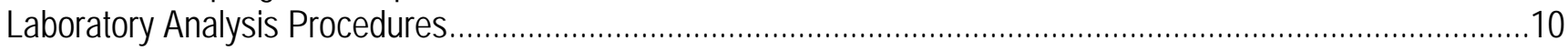

Field Portable XRF (FPXRF) Sampling and Analysis Procedures..............................................................10

Quality Assurance and Quality Control in XRF Data Collection...................................................................11

Interferences and Potential Problems................................................................................................11

ASD Full-Range Spectrometer Sampling and Analysis Procedures.............................................................12

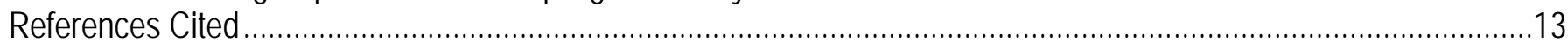

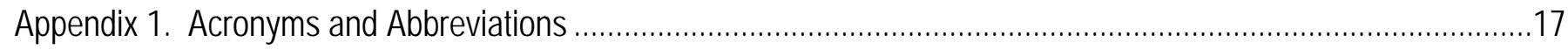

\section{Tables}

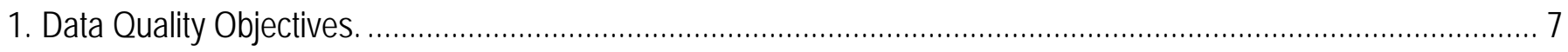

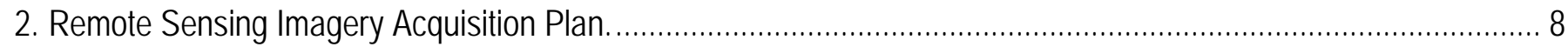




\title{
Research Implementation and Quality Assurance Project Plan: An Evaluation of Hyperspectral Remote Sensing Technologies for the Detection of Fugitive Contamination at Selected Superfund Hazardous Waste Sites
}

\author{
By E. Terrence Slonecker and Gary B. Fisher
}

Introduction

This project is a research collaboration between the U.S. Environmental Protection Agency (EPA) Office of Inspector General (OIG) and the U.S. Geological Survey (USGS) Eastern Geographic Science Center (EGSC), for the purpose of evaluating the utility of hyperspectral remote sensing technology for post-closure monitoring of residual contamination at delisted and closed hazardous waste sites as defined under the Comprehensive Environmental Response Compensation and Liability Act [CERCLA (also known as "Superfund")] of 1980 and the Superfund Amendments and Reauthorization Act (SARA) of 1986.

\section{Background}

The Office of Inspector General is an independent office within the EPA that helps the Agency protect the environment in a more efficient and cost-effective manner. The OIG consists of auditors, program analysts, investigators, and others with extensive expertise. Although the OIG is a part of the EPA, Congress provides OIG with funding separate from the Agency, to ensure independence. The OIG was created pursuant to the Inspector General Act of 1978.

The mission of the EPA OIG is to perform independent work that helps ensure the integrity of EPA programs and operations by preventing waste, fraud, and abuse while promoting economy, efficiency, and effectiveness. The OIG proposes innovative ideas and constructive solutions to EPA management and others, including Congress, and provides detailed reports that lead to positive change in the environment and improvements in EPA's business practices and accountability. Twice a year, the OIG provides a semiannual report to Congress that identifies significant EPA deficiencies, and that proposes corrective actions and profiles accomplishments. The OIG also reviews public complaints about EPA programs and activities.

As part of the OIG's oversight of the EPA, the OIG will assess the utility of using remote sensing data as an oversight tool to assess the adequacy of the EPA's decisions to "delist" Superfund sites. The U.S. Geological Survey (USGS) Eastern Geographic Science Center (EGSC) agrees to assist the EPA OIG by developing and testing hyperspectral remote sensing technologies for the detection of fugitive and residual contamination at delisted hazardous waste sites as defined under the CERCLA.

The advancement of geographic science in the area of land surface status and trends and land cover change is at the core of the USGS current geographic scientific research agenda (McMahon and others, 2005). The dynamics of change on the Earth's surface, and its causes, consequences, and drivers, relate to several strategic goals of the Geographic Analysis and Monitoring (GAM) Program (USGS, 
2006), the Geospatial Information Office (GIO) (Siderelis, 2005), the Land Remote Sensing (LRS) Program (LRS, 2008), the National Land Imaging Program (NLIP)(FLIIWG, 2007), the Geographic Discipline (McMahon and others, 2005), the Bureau (USGS, 2000) and the U.S. Department of the Interior strategic goals (USDOI, 2006).

Using the expertise of remote sensing personnel at the USGS EGSC and existing USGS EGSC equipment and software, the EGSC will evaluate the use of field and overhead hyperspectral data for the identification of contamination at up to 10 delisted Superfund sites. This evaluation assessment will focus on an initial sample of up to five sites. After completion of the analytical work for these initial sites, the USGS and the EPA will meet to discuss the results of that analysis, the effectiveness of the remote sensing technology, and the feasibility of continuing the evaluation with an additional sample of sites.

\section{Remote Sensing of Hazardous Waste}

Remote sensing is becoming an increasingly important science for advancing understanding of environmental processes, conditions, and changes for both human and ecological health. Significant advancements in sensor technology and processing algorithms have resulted in technical capabilities that can record and identify earth surface materials based on the interaction of electromagnetic energy with the molecular structure of the material being sensed. Hyperspectral remote sensing (HRS) records reflected and emitted electromagnetic energy in hundreds of very narrow wavelengths, which result in data that can be analyzed with the same chemical spectroscopic techniques that have been used by chemists and astronomers for decades. In addition, new analytical techniques are constantly being developed and refined that permit the identification and analysis of key environmental processes, such as photosynthesis and nutrient cycling.

Spectral reflectance of vegetation and other landscape conditions has received renewed interest by the remote sensing community during the past decade because of the development of this new class of imaging technology. Many of the early and definitive studies in spectral reflectance utilized spectroscopic measurement instruments in a laboratory setting. These instruments measured reflected energy and produced spectra, which could then be analyzed using standard spectroscopic techniques.

The collection of hyperspectral imagery in very narrow bandwidths across the solar-reflected part of the electromagnetic spectrum (EMS) results in a digital file of hundreds of bands of coregistered imagery, sometimes called a "data cube." After processing, this data cube essentially represents an imagery version of the same energy and matter interactions that are measured in the laboratory and can be analyzed with a variety of standard and emerging statistical methods in spectroscopy and remote sensing. Reflected spectral patterns can identify certain compounds, materials, and conditions based on the interaction of photons with the molecular structure of the target material. Spectroscopic analysis techniques can now be employed outside of the laboratory through the use of HRS-imaging techniques and portable field spectroradiometers. The objective of this research is to evaluate hyperspectral imagery (HSI) and field spectroscopic measurement techniques in the characterization and analysis of fugitive contamination at selected hazardous waste disposal sites.

\section{Research Implementation Plan}

This research seeks to determine if hyperspectral remote sensing can be used effectively to monitor the contamination profile at hazardous waste sites, especially those that have been deleted from or that have not been selected for priority cleanup on the National Priorities List (NPL) of the Superfund Program. The primary contamination issues involve the presence of heavy metals; however, 
other contaminants, such as volatile organic compounds (VOCs), landfill leachate, pesticides, or other organic pollutants, may also be identified.

New and (or) existing hyperspectral imagery will be collected or acquired over five Superfund sites selected by the EPA. The USGS will research the background and contamination history of each site and will process and analyze the hyperspectral imagery to determine if any evidence of potential fugitive contamination exists. If any unusual chemical compounds or secondary vegetation stress signatures are identified by hyperspectral imagery analysis, the individual sites will be visited to identify and map any contamination issues at the site based on field spectroscopy, soil, vegetation, or water sampling, and laboratory and (or) x-ray fluorescence (XRF) results. All field visits will be closely coordinated with the EPA OIG and the EPA regional contacts. Two primary contamination threshold issues will be addressed: (1) evidence of contamination above background levels and (2) evidence of contamination above action levels. If there is evidence of contamination above action levels, the EPA will be notified immediately. A full report for each site will be prepared, including the methods and results of both the field and imagery-hyperspectral processing, as well as the results of the laboratory sampling.

Six main components of this research are as follows:

1. Site identification and preliminary research;

2. Overhead HSI data collection and acquisition;

3. Overhead HSI data processing;

4. Site visit and field data collection;

5. Field data analysis; and

6. Individual site report.

1. Site identification and preliminary research: A preliminary list of potential Superfund sites of interest will be provided to the EGSC by the EPA prior to the project start. The EGSC will evaluate each site for potential research interest, including a review of the history at activities of the site; acquisition and review of historical documents, such as the preliminary assessment; historical maps and aerial photographs; and existing sampling results. The EGSC will generate a site-specific plan for spectral and laboratory sample collection for the overall site, as well as for candidate areas of potential contamination. This will also include a review of recent high-resolution spatial and spectral information to determine if any areas on the site, or in the immediate areas adjacent to the site, display any landscape characteristics, such as vegetation stress, which might indicate areas of residual pollution. This will result in the development of a conceptual site model for current potential contamination at the site and the development of an initial sampling plan for the site.

2. Overhead HSI data collection: Research will be conducted on the metadata records for archival hyperspectral systems to determine if any existing hyperspectral imagery of the site is available and appropriate for analysis. Systems to be searched include the NASA AVIRIS system (http://aviris.jpl.nasa.gov/html/aviris.quicklooks.html) and the EO-1 Hyperion System (http://edcsns17.cr.usgs.gov/EarthExplorer/). Any existing HSI will be acquired and processed for fugitive contamination analysis. If the data of the existing hyperspectral imagery predates the site 
delisting, research on the site history will be conducted in order to match the site contamination profile at the time of the HSI overflight.

3. Overhead HSI data processing: A variety of image-processing techniques will be employed to determine if any signature of fugitive contamination is contained in the hyperspectral imagery. These include the following:

Spectral analyst Standard automated spectral processing as defined in ENVI (Boulder, Colorado) "Spectral Analyst” image-processing software.

Vegetation indices A variety of vegetation indices will be computed and evaluated against known site conditions. The vegetation indices (VI) that will be used will depend on the hyperspectral sensor being used. A listing of relevant VIs can be found in the documentation for ENVI Image Processing software and Slonecker (2007).

Endmember analysis Endmember analysis is a Bayesian statistical model that attempts to isolate a variable or sets of variables that appear to drive a particular process. In hyperspectral image-processing applications, endmembers are spectrally "pure” pixels that influence various mixture models. In certain applications, endmembers could be a dominant chemical or element that influences landscape condition.

MF and MTMF

Matched filters (MFs) and mixture-tuned matched filters (MTMFs) are common image-processing techniques that are used to improve the signal-to-noise ratio in imagery. Commonly used in the area of signal processing, a matched filter is obtained by cross-correlating a known signal, or spectral mixture, with an unknown signal or spectra to detect the presence of the template in the unknown signal. A matched filter is essentially a linear optimization of the signal-to-noise ratio. MTMFs statistically constrain the matched filtering as mixtures of the stochastic background noise and the target spectral signature. MTMFs produce the standard MF results and an additional set of probability images for each endmember called "infeasibility images.”

PLS and SLR Partial least squares (PLS) and stepwise linear regression (SLR) are data mining and modeling techniques that are used in laboratory spectroscopy applications.

4. Site visit and field data collection: If any potential contamination signature is identified in the analysis of the overhead hyperspectral imagery, USGS will conduct a site visit to collect in-place samples. (Note: If no contamination signature can be identified in the hyperspectral imagery analysis, the USGS will not conduct a field visit and will procede to analyze a new site during preliminary research. Coordinating with the EPA, the EGSC will visit the site and conduct a field data collection to include the following: 
1. XRF analysis of soils for heavy metals;

2. Collection of in-place soil samples;

3. Collection of in-place vegetation samples; and

4. Collection of spectral reflectance of soil and vegetation.

As a quality control process, approximately 5 percent of all XRF and soil samples and all vegetation samples will be collected in place and sent to the USGS Laboratory in Denver, Colo., for analysis by standard laboratory methods, such as inductively coupled plasma/atomic emission spectrometry (ICP/AES) methods.

5. Field data analysis: XRF, spectral, and in-place sampling data will be processed to determine the contaminant profile at the site. Statistical techniques will include kriging, partial least squares, and the analysis of spectral indices. Analysis products that will be developed are special maps, tables, and imagery products to demonstrate the pattern and levels of contamination at the site.

If necessary, a second site visit and data collection will be coordinated with the EPA. A second site visit might be required to collect additional data in areas exhibiting unusually high signatures of contamination, to better clarify spatial or spectral patterns, or to provide calibration for an overhead spectral data collection. Also, if the contamination profile present does not correlate with heavy metals in the soil, then additional soil sampling might be required for volatile organic compounds (VOCs), leachate, and (or) other contaminants.

6. Site report: After the analysis of both the remote sensing and field data, USGS will prepare a site report that details the results of the analyses - the quality assurance (QA) evaluation-and that specifies the technical parameters of each potential signature of contamination.

\section{Deliverables}

Deliverables under this project include the following:

1. Weekly conference calls;

2. Informal (e-mail) reports for each site analyzed;

3. An interim report of progress for the first 6 months, to be delivered by April 30, 2009;

4. A final project report, to be delivered by November 1, 2009; and

5. Other papers, posters, and presentations, as appropriate.

\section{Quality Assurance Project Plan}

In Section 515(a) of the Treasury and General Government Appropriations Act for Fiscal Year 2001 (Public Law 106-554; HR 5658), Congress directed the Office of Management and Budget (OMB) to issue Governmentwide guidelines that "provide policy and procedural guidance to Federal agencies for ensuring and maximizing the quality, objectivity, utility, and integrity of information (including statistical information) disseminated by Federal agencies." OMB's guidelines were published in the Federal Register on February 22, 2002 (67 FR 8452). 
The mission of the USGS is to serve the Nation by providing reliable scientific information to: (1) describe and understand the Earth; (2) minimize loss of life and property from natural disasters; (3) manage water, biological, energy, and mineral resources; and (4) enhance and protect the quality of life.

The USGS provides unbiased, objective scientific information upon which other entities may base judgments. Since the Bureau's inception in 1879, the USGS has maintained comprehensive internal and external procedures for ensuring the quality, objectivity, utility, and integrity of data, analyses, and scientific conclusions. These information quality guidelines cover all information produced by the USGS in any medium, including datasets, Web pages, maps, audiovisual presentations, USGSpublished reports, or reports by USGS authors published by others.

USGS information is published in many media, and because of the scientific nature of the information, it passes through many quality-assurance reviews, including peer review, to ensure the utility, objectivity, and integrity of the information. These quality review standards are published by the USGS at: $h t t p: / / w w w . u s g s . g o v / u s g s-m a n u a l / 500 / 502-4 . h t m l$. Information on the quality-assurance procedures at the USGS can be found at http://www.usgs.gov/info_qual/.

The EPA Quality System defined in EPA Order 5360.1 A2, Policy and Program Requirements for the Mandatory Agency-wide Quality System (EPA, 2000b), includes coverage of environmental data or "any measurement or information that describes environmental processes, location, or conditions; ecological or health effects and consequences; or the performance of environmental technology. For the EPA, environmental data includes information collected directly from measurements, produced from models, and compiled from other sources such as databases or literature.” The EPA Quality System is based on an American National Standard, ANSI/ASQC E4-1994.

Consistent with the National Standard, E4-1994, it is EPA policy [Section §6.a.(7) of EPA Order 5360.1 A2] that EPA organizations develop a quality system that includes "approved Quality Assurance Project Plans (QAPPs), or equivalent documents defined by the Quality Management Plan, for all applicable projects and tasks involving environmental data with review and approval having been made by the EPA QA Manager (or authorized representative defined in the Quality Management Plan). More information on the EPA's policies for QA Project Plans is provided in Chapter 5 of the EPA Manual 5360 A1, EPA Quality Manual for Environmental Programs covering EPA (EPA, 2000a) and Requirements for Quality Assurance Project Plans (QA/R-5) covering non-EPA organizations (EPA, 2001b). This guidance helps to implement the policies defined in Order 5360.1 A2, and polices governing geospatial data (EPA, 2003).

\section{Geospatial Data}

\section{Data Quality Objectives}

Data quality objectives (DQOs) are qualitative and (or) quantitative statements of the overall level of accuracy that is being sought by a researcher's measurement process or the uncertainty that a decisionmaker will accept in results. DQOs provide the statistical framework for planning and managing geospatial data operations consistent with the needs of the project.

Because the remote sensing and Geographic Information Systems (RS \& GIS) data is originating from disparate sources, reviews will be conducted to ensure the quality of the final data products is maintained. Metadata and content standards will be applied to all data being utilized in the project, according to Federal Geospatial Data Committee standards (FGDC, 2002) and the National Spatial Data Infrastructure (NSDI) (Clinton, 1994). 
Table 1. Data quality objectives.

\begin{tabular}{|c|c|c|c|c|}
\hline Data name and type & Source & $\begin{array}{c}\text { Derived } \\
?\end{array}$ & $\begin{array}{l}\text { Performance } \\
\text { Criteria } \\
\text { (derived data) }\end{array}$ & Acceptance Criteria \\
\hline Field GPS & Field collection, 2008 & Yes & $+/-2$ meter & +/- 2 meter \\
\hline Field spectral data & Field collection, 2008 & Yes & +/- 2 meter & +/- 2 meter \\
\hline $\begin{array}{l}\text { Field portablex-ray } \\
\text { fluorescence data }\end{array}$ & Field collection, 2008 & Yes & $+/-2$ meter & +/- 2 meter \\
\hline $\begin{array}{l}\text { Field soil/vegetation } \\
\text { samples }\end{array}$ & Field collection, 2008 & Yes & +/- 2 meter & +/- 2 meter \\
\hline Airborne data & $\begin{array}{l}\text { CAP/ARCHER } \\
\text { AVIRIS, Others }\end{array}$ & No & & $\begin{array}{l}+/-1 \text { pixel (nominal } 4 \mathrm{~m} \mathrm{x} \\
4 \mathrm{~m})\end{array}$ \\
\hline $\begin{array}{l}\text { Satellite data: Hyperion, } \\
\text { satellite data: CHRIS }\end{array}$ & $\begin{array}{l}\text { U.S. Geological Survey } \\
\text { European Space } \\
\text { Agency }\end{array}$ & No & & $\begin{array}{l}+/-1 \text { pixel (nominal 30m x } \\
\text { 30m) }\end{array}$ \\
\hline GIS data - raster & U.S. Geological Survey & $\begin{array}{l}\text { Yes, } \\
\text { some }\end{array}$ & $+/-2$ meter & $\begin{array}{l}+/-1 \text { pixel (nominal 30m x } \\
\text { 30m) }\end{array}$ \\
\hline GIS data - vector & U.S. Geological Survey & $\begin{array}{l}\text { Yes, } \\
\text { some }\end{array}$ & +/- 2 meter & $\begin{array}{l}\text { +/- } 1 \text { minimum mapping unit } \\
\text { (varies) }\end{array}$ \\
\hline
\end{tabular}


Table 2. Remote sensing imagery acquisition plan.

\section{RS Imagery Acquisition Plan}

Geographic extent of data to be acquired (that is, size, shape, and location of study area)
Field and overhead hyperspectral and chemical data will be collected for 5-10 delisted Superfund sites to be determined by the EPA.
Is data listed in table 1 to be collected for this project or purchased from existing data source?

What is the sampling design related to imagery acquisition?
The majority of data will be specifically collected and purchased for this project. In the unlikely circumstance that acceptable hyperspectral imagery exists from another source, it will be acquired instead of being collected by contract overflight.

Imagery acquisition in each study location is a complete coverage of the Superfund site boundary and the surrounding area.

What final surface characteristics Areas of soil contamination and vegetation stress as determined by will be derived from imagery (for analysis of in-place, handheld, and overhead imagery. example, vegetation type, canopy cover, soil type, vegetation stress)?

What film products are to be used?
Historical aerial photographs (1930s-1990s) of the individual sites may be used.
During what time(s) of year will the study take place?
The study will primarily use summer data, although the in-place collection of data could occur at any time during the year.
What spatial and spectral resolution(s) are required to accomplish the project goals?
Spectral resolution will vary from 52 bands and approximately 15-20 nanometers $(\mathrm{nm})$ per band with the ARCHER airborne sensor to approximately 242 bands at 10 nanometers per band (Hyperion hyperspectral satellite data). Spatial resolution could vary between 1 and 30 meters, depending on imagery source.
What georegistration techniques will be accepted?
See table 1. Digital orthophoto quarter quadrangle (DOQQ) standards for aerial data and NLCD standards for satellite data (Vogelmann and others, 2001).
How will the imagery be delivered?
(1) Internet download or

(2) mail courier:

a. DVD (hyperspectral imagery), or 
b. compact disk (all other data)

What supporting documentation will be provided?
Metadata per Federal Geospatial Data Committee (2002; http://www.fgdc.gov/) standards, as per NSDI (Clinton, 1994).
How will relevant climatic factors be mitigated?
Data standard: 0 percent cloud cover required to produce land cover where applicable.

\section{Field Sampling and Analysis}

Most of the field sampling and analysis procedures that will be utilized in this research project are based on well-established protocols that have been developed by both the EPA and the USGS. This is especially true for soil-, vegetation- and sediment-sampling procedures, as well as for analytical chemistry via inductively coupled plasma (ICP) and atomic emission spectrometry (AES). When this is the case, document references and hyperlinks are provided for the sake of simplicity and paperwork reduction. Because they are more experimental, more detailed procedures are provided below for the $\mathrm{XRF}$ and visible/near-infrared (VIS/NIR) spectroscopic procedures that will be used in the field.

\section{Soil-Sampling and Preparation Procedures}

Soil is the major contamination media being investigated in this research. Unacceptable levels of heavy metals, VOCs, and other contaminants are being targeted for identification by hyperspectral analysis methods. All soil sampling and preparation will be conducted according to standard operating procedures (SOPs) from both EPA and USGS methods, as outlined in Mason (1983), Barth and Mason (1984), Peacock (1993), available at http://pubs.usgs.gov/of/2002/ofr-02-0223/A3SoilPrep_M.pdf, and EPA (2002), available at http://www.ert.org/products/2012.pdf.

These standard operating procedures describe the methods that will be used for the collection of representative surface or near-surface soil samples. Sampling depths will not exceed 6 inches.

\section{Vegetation-Sampling and Preparation Procedures}

Ecological assessments of hazardous waste sites are required under the Comprehensive Environmental Response, Compensation and Liability Act (CERCLA) and the Superfund Amendments and Reauthorization Act (SARA). Vegetation is an important component of any ecosystem and is generally easily collected and measured at a hazardous waste site. For this research, vegetation is a critical component and the primary spectral indicator of soil and (or) subsurface contamination. The goal of this hyperspectral remote sensing research is to determine the value in extracting subtle spectral indicators of vegetation stress due to soil or surface contaminations. Although it is possible to directly detect metals, VOCs, and other contaminants, the mostly likely indicator from a remote sensing perspective will be the health and reflectance characteristics of the surface vegetation. 
When soil contamination is identified and (or) there are visible signs of stress in the surface vegetation, samples will be collected and prepared for laboratory analysis. Procedures for vegetation sampling and preparation are documented by USGS Procedures in Peacock and Crock (2001), available at http://pubs.usgs.gov/of/2002/ofr-02-0223/B17PlantAsh_M.pdf, and bythe EPA (1994b, 1996),

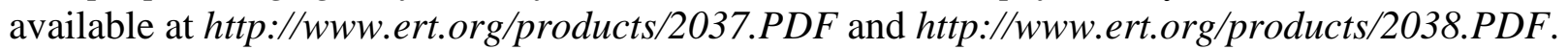

\section{Sediment Sampling and Preparation Procedures}

Although not the primary focus of this research, stream sediments could be a primary indicator of the transport and movement of contaminants, and in some cases, as with iron oxides, there is a strong spectral indicator of individual mineralogy (Anderson and Robbins, 1998). XRF is not generally used in the field for sediment samples because water generally interferes with XRF analysis. Sediment samples will be collected, dried, and prepared for chemical analysis by laboratory and (or) laboratory XRF methods. Samples require preparation to effect one or more of the following: (1) reduce the sample to a size that is more conveniently transported; (2) increase the sample surface area to enhance the efficiency of subsequent chemical attack; (3) homogenize the sample to ensure that a subsample is representative of the entire sample; and (4) separate the sample into components based on mineralogy, grain size, or other physical and morphological criteria. Sample preparation is an important step in the analytical process. Without careful preparation and attention to intersample contamination, the worth of the subsequent analyses is significantly diminished. Sediment sampling and preparation will be conducted in accordance with established USGS (Peacock and others, 1993) and EPA (1994a) procedures.

\section{Laboratory Analysis Procedures}

All confirmatory and quality-control laboratory analysis of field samples will be conducted by ICP/AES methods in accordance with USGS procedures (Taggart, 2002) and EPA Method 6010 for total metals.

\section{Field Portable XRF (FPXRF) Sampling and Analysis Procedures}

XRF data collection and analysis utilizes low-level x-ray sources to irradiate sample material. When a sample is irradiated, source $\mathrm{x}$-rays may be absorbed by sample atoms, producing what is known as the photoelectric effect. The process of absorption results in the emission of fluorescent x-rays whose energies are uniquely characteristic of specific elements. XRF instruments excite samples and then use the resulting fluorescent emissions to identify the elements present and estimate their concentrations. In general, XRF can be used for metals with an atomic number of 16 or greater. Detection limits for any individual element depend on a variety of factors, including count times, excitation source and strength, sample preparation, matrix effects, and interelement spectral interferences (Kalnicky and Singhvi, 2001; ANL, 2004).

XRF systems can be deployed in a laboratory setting or as field portable instruments. Measurements can be made on prepared samples, or in place on the soil surface; in both cases, the detector window is pressed against a sample's (or subsample's) surface. An XRF instrument typically measures concentrations in a very small subsample of an original sample; proper sample homogenization is critical to ensuring replicability and adequate precision in measurements. Measurement times typically range from 60 to 600 seconds. Although the XRF instrument is not measuring radioactivity of material, the measurement analysis involves the same type of spectroscopy as radionuclide measurements (for example, gamma and alpha spectroscopy); therefore, the same 
principals of counting errors and counting statistics as a function of count times apply (ANL, 2004; EPA, 2007).

XRF has made steady gains in regulatory acceptance for heavy metal characterization, including its inclusion in EPA SW-846 as Method 6200 (EPA, 2007). The EPA's Method 6200 reports excellent method performance for some metals (for example, arsenic, copper, lead, and zinc) as compared to confirmatory laboratory analyses. XRF is currently used widely to characterize heavy metals (particularly lead) in environmental media.

The general conduct and standard operating procedures of an XRF analyzer in the field are established by protocols of both the USGS (Siems, 2002) and the EPA (2007), and by the SOPs of the manufacturer (Shefsky, 1998; Thermo-Fisher Scientific, 2007). However, because of the critical nature of the XRF analysis in this research, additional quality assurance and quality control (QA/QC) processes for XRF data collection are being articulated in greater detail here.

\section{Quality Assurance and Quality Control in XRF Data Collection}

Interferences and Potential Problems

Total method error for XRF analysis is a combination of both instrument precision and user- or application-related error. Instrument precision is typically the least significant source of error in XRF analysis (EPA, 1991). User- or application-related error is generally more significant and will vary with each site and method used. Specific QA/QC procedures designed to minimize user- and (or) applicationrelated errors include the following:

1. Soil preparation and sample placement: This is a potential source of error because the x-ray signal decreases as the distance from the $x$-ray source is increased. This error may be minimized by maintaining the same distance for each sample and by homogenizing samples to the greatest extent possible. Sample geometry with respect to the x-ray tube or detector is also important. This can be largely controlled with the use of the XL3 test stand and the proper soil preparation procedures for discrete sample analysis (Thermo Fisher Scientific, 2006). Whenever feasible, this stand will be utilized to control sample placement variability, especially when in-place readings indicate elevated levels of contamination.

2. Representativeness: To accurately characterize site conditions, samples collected must be representative of the site or area under investigation. Representative soil sampling ensures that a sample or group of samples accurately reflects the concentration of the contaminant(s) of concern at a given time and location. Variables affecting sample representativeness include: (1) geologic variability, (2) contaminant concentration variability, (3) collection and preparation variability, and (4) analytical variability. Representativeness will generally be established by a regular grid over the site area that may be augmented by additional samples in areas of potential contamination as determined from the preliminary analysis of the site history.

3. Reference analysis: One of the most effective methods of quality control in the use of FPXRF technology is the use of reference analysis of soil samples by laboratory ICP/AES or equivalent laboratory methods. Soil chemical and physical matrix effects may be corrected (to some extent) by adjusting XRF results (via regression) using site-specific soil samples that have been analyzed by ICP/AES laboratory methods. A major source of error can result if these samples are not representative of the site and (or) if the analytical error is large. At a minimum, 5 percent of all FPXRF in-place samples will be duplicated by ICP/AES laboratory analysis (Thermo Fisher Scientific, 2007) and will be compared against field samples according to methods outlined in EPA Method 6200 (EPA, 2007). 
4. Calibration Check-Blank Samples: EPA Method 6200 recommends the periodic use of blank samples from a "clean" quartz or silicon dioxide matrix that is free of any analytes at concentrations above the established lower limit of detection. These samples are used to monitor for cross-contamination and laboratory-induced contaminants or interferences. A standard reference "blank" sample ( $\mathrm{SiO} 2$ ) is provided by the manufacturer and will be used for instrument calibration purposes.

5. Calibration Check-Standard Reference Materials: Standard reference materials (SRMs) are standards containing certified amounts of metals in soil or sediment. These standards are used for accuracy and performance checks of FPXRF analyses. SRMs can be obtained from the National Institute of Standards and Technology (NIST), the USGS, the Canadian National Research Council, and the national bureau of standards in many foreign nations. SRMs are provided by the instrument manufacturer and comply with NIST Standard 2780.

\section{ASD Full-Range Spectrometer Sampling and Analysis Procedures}

An Analytical Spectral Devices (ASD) full-range spectrometer will be utilized to collect hyperspectral field data. The ASD utilizes a fiber optic sensor and a bank of grating spectrometers to collect electromagnetic energy in 1-nm intervals between $350-2500 \mathrm{~nm}$, the "solar reflected" portion of the electromagnetic spectrum. Its nominal spatial, sampling, and resolution specifications make it well suited to the collection of field data for correlation with hyperspectral imagery applications (Curtiss and Goetz, 1994). The full technical and quality-control considerations for operation of the ASD full-range spectrometer can be found in Hatchell (1999).

The ASD spectrometer has been utilized in numerous hyperspectral imagery research applications (Perry and Roberts, 2008; Slonecker, 2007; Clark and others, 2003). Significant operational QA/QC considerations for the ASD spectrometer are primarily internal calibration, instrument optimization, white-reflectance reference collection, and multiple spectral data collections per target. The EGSC ASD spectrometer was recently (October 2008) upgraded and calibrated to factory specifications by the manufacturer, ASD Incorporated (Boulder, Colo.).

For field operation, the ASD is connected to a Panasonic Toughbook laptop computer that is used to execute the spectral collection instrument software. The fiber optic cable of the spectrometer is housed in a pistol grip assembly and mounted on a standard camera tripod to be perpendicular to the target surface. Spectra are calibrated against a white Spectralon surface and processed according to the standard techniques outlined in Hatchell (1999). When used outside, the spectrometer utilizes solar light and is generally collected with $+/-2$ hours of solar noon. When used in a laboratory setting, a Lowell lamp is used as a solar-quality light source for all spectral collections and is mounted on a 60-degree angle to the spectral target.

Each spectral collection event utilizes nine observations and is conducted according to the following standard procedures:

1. Optimization of the spectrometer (internal calibration);

2. Collection of two white references (WR) from the Spectralon standard;

3. Collection of five spectral readings from the target, altering the target orientation or slightly moving the sample after each reading; and

4. Collection of two white references from the Spectralon standard. 
5. Spectra are processed by standard techniques based on the following general formula for relative reflectance (ASD, 1997):

Reflectance (Band_x) $=(($ Radiance $($ Band_x) $/$ White Ref. (Band_x $) * 100) *$ Ref. Std. (Band_x))

\section{References Cited}

Anderson, J.E., and Robbins, E.I., 1998, Spectral reflectance and detection of iron-oxide precipitates associated with acidic mine drainage: Photogrammetric Engineering and Remote Sensing, v. 64, no. 12, p. 1201-1208.

ANL (Argonne National Laboratory), 2004, DRAFT: Applicability of x-Ray fluorescence (XRF) for Rattlesnake Creek Environmental Assessment Division: Argonne National Laboratory, available online at http://www.clu-in.org/conf/tio/xrf_082508/cd/Demonstration-of-Method-ApplicabilityExamples/XRFappstudy020404.pdf.

ASD (Analytical Spectral Devices, Inc.), 1997, FieldSPEC User's Guide, Manual Release: Boulder, Colo., Analytical Spectral Devices, Inc.

Barth, D.S., and Mason, B.J., 1984, Soil sampling quality assurance user's guide: Washington, D.C., U.S. Environmental Protection Agency Report EPA-600/4-84-043.

Clark, R.N., Swayze, G.A., Wise R., Livo, K.E., Hoefen, T.M., Kokaly, R.F., and Sutley, S.J., USGS Digital Spectral Library splib05a: U.S. Geological Survey Open File Report 03-395, available online at $h t t p: / / p u b s . u s g s . g o v / o f / 2003 / o f r-03-395 / o f r-03-395 . h t m l$.

Clinton, W.J., 1994, Coordinating geographic data acquisition and access: Washington, D.C., The National Spatial Data Infrastructure, Executive Order 12906, v. 59, no. 71, p. 17671-17674.

Comprehensive Environmental Response, Compensation, and Liability Act (CERCLA; commonly known as Superfund), 1980, Public Law 96-510, 42 U.S.C. §§ 9601 et seq.

Curtiss, B., and Goetz, A.F.H., 1994, Field spectrometry: Techniques and instrumentation $\underline{\text { in }}$ [technical works presented at] the International Symposium on Spectral Sensing Research (ISSSR), San Diego, Calif., July 1994.

EPA (U.S. Environmental Protection Agency), 1991, Field-portable x-ray fluorescence: U.S. EPA/ERT Quality Assurance Technical Information Bulletin, v. 1, no. 4, 4 p.

EPA, 1994a, Environmental Response Team, standard operating procedures—sediment sampling: U.S. Environmental Protection Agency, SOP \#2016, 11 p., available online at http://www.ert.org/products/2016.PDF.

EPA, 1994b, Environmental Response Team, standard operating procedures—-terrestrial plant community sampling: U.S. Environmental Protection Agency, SOP \#2037, 6 p., available online at http://www.ert.org/products/2037.PDF. 
EPA, 1996, Environmental Response Team, standard operating procedures—vegetation assessment field protocol: U.S. Environmental Protection Agency, SOP \#2038, 17 p., available online at http://www.ert.org/products/2038.PDF.

EPA, 2000a, EPA Quality Manual for Environmental Programs, CIO 2105-P-01-0: Washington, D.C., U.S. Environmental Protection Agency, 62 p., available online at http://www.epa.gov/irmpoli8/ciopolicy/2105-P-01-0.pdf.

EPA, 2000b, Policy and Program Requirements for the Mandatory Agency-wide Quality System, CIO 2105.0: Washington, D.C., U.S. Environmental Protection Agency, 12 p., available online at http://www.epa.gov/irmpoli8/ciopolicy/2105-0.pdf.

EPA, 2002, Environmental Response Team, standard operating procedures—soil sampling: U.S. Environmental Protection Agency, SOP \# 2012, 13 p., available online at http://www.ert.org/products/2012.pdf.

EPA, 2003, Guidance for Geospatial Data Quality Assurance Project Plans (EPA QA/G-5G): Washington, D.C., U.S. Environmental Protection Agency Office of Environmental Information, EPA/240/R-03/003, 106 p.

EPA, 2007, Method 6200, Field portable x-ray fluorescence spectrometry for the determination of elemental concentrations in soil and sediment: Washington, D.C., U.S. Environmental Protection Agency, February 2007, 32 p., available online at http://epa.gov/osw/hazard/testmethods/sw846/pdfs/6200.pdf.

FGDC (Federal Geographic Data Committee), 2002, Content standard for digital geospatial metadata, extensions for remote sensing metadata: Federal Geographic Data Committee Document Number FGDC-STD-012-2002, 140 p, available online at http://www.fgdc.gov/standards/projects/FGDCstandards-projects/csdgm_rs_ex/MetadataRemoteSensingExtens.pdf.

FLIIWG (Future Land Imaging Interagency Working Group), 2007, A plan for a U.S. national land imaging program: National Science and Technology Council, Executive Office of the President of the United States, 120 p., available online at http://www.landimaging.gov/fli_iwg_report_print_ready_low_res.pdf.

Hatchell, D.C., ed. 1999, Analytical spectral devices (ASD) technical guide, fourth edition: Boulder, Colo., Analytical Spectral Devices, Inc., 136 p., available online at http://www.asdi.com/tg_rev4_web.pdf.

Kalnicky, D.J., and Singhvi, .R., 2001, Field portable XRF analysis of environmental samples: Journal of Hazardous Materials, v. 83, nos.1-2, p. 93-122.

LRS (Land Remote Sensing), 2008, USGS Land Remote Sensing Program, research and applications: U.S. Geological Survey Web site, accessed February 5, 2009, at http://remotesensing.usgs.gov/researchapps.php. 
Mason, B.J., 1983, Preparation of soil sampling protocol, technique and strategies: Washington, D.C., U.S. Environmental Protection Agency Report EPA-600/4-83-020.

McMahon, G., Benjamin, S.P., Clarke, K., Findley, J.E., Fisher, R.N., Graf, W.L., Gunderson, L.C., Jones, J.W., Loveland. T.R., Roth, K.S., Usery, E.L., and Wood, N.J., 2005, Geography for a changing world-A science strategy for the geographic research of the U.S. Geological Survey, 2005-2015: U.S. Geological Survey Circular 1281, 76 p. (Also available online at http://geography.usgs.gov/documents/USGSGeographySciencePlan.pdf.)

Peacock, T.R., 1993, Soil sample preparation, in Chapter A3, Analytical methods for chemical analysis of geologic and other materials: U.S. Geological Survey Open-File Report 02-223-A3 (J.E. Taggart, ed.), available online at $h t t p: / / p u b s . u s g s . g o v / o f / 2002 / o f r-02-0223 / A 3 S o i l P r e p \_M . p d f$.

Peacock, T. R., and Crock, J.G, 2001, in Chapter B: The preparation of plant material and determination of weight percent ash: U.S. Geological Survey Open-File Report 02-223-B (J.E. Taggart, ed.), available online at http://pubs.usgs.gov/of/2002/ofr-02-0223/B17PlantAsh_M.pdf.

Peacock, T.R. , Taylor, C.D., and Theodorakos, P.M., 1993, Stream-sediment sample preparation, in Chapter A2, Analytical methods for chemical analysis of geologic and other materials: U.S. Geological Survey Open-File Report 02-223-A2 (J.E. Taggart, ed.), available online at http://pubs.usgs.gov/of/2002/ofr-02-0223/A2SedPrep_M.pdf.

Perry, E.M., and Roberts, D.A., 2008, Sensitivity of narrow-band and broad-band indices for assessing nitrogen availability and water stress in an annual crop: Agronomy Journal, v. 100, no. 4, p. 12111219.

SARA, 1986, Superfund Amendments and Reauthorization Act, Public Law 99-499, 42 U.S.C. §§ 9601 et seq.

Shefsky, Stephen, 1998, Comparing field portable x-ray fluorescence (XRF) to laboratory analysis of heavy metals in soils, in [technical works presented at] the International Symposium of Field Screening Methods for Hazardous Waste and Toxic Chemicals, January 29-31, 1997, Las Vegas, Nev.: Billerica, Mass., NITON Corporation, available online at http://www.clu-in.org/download/char/dataquality/sshefsky02.pdf.

Siems, D.F, 2002, The determination of 30 elements in geological materials by energy-dispersive x-ray fluorescence spectrometry, in Chapter U, Analytical methods for chemical analysis of geologic and other materials: U.S. Geological Survey Open-File Report 02-223-U (J.E. Taggart, ed.), 13 p., available online at http://pubs.usgs.gov/of/2002/ofr-02-0223/U27edsfinal_U.pdf.

Slonecker, E.T., 2007, Remote sensing of fugitive arsenic and its effect on vegetation reflectance: Fairfax, Va., George Mason University, Ph.D. dissertation, 255 p.

Taggart, J.E. (ed.), 2002, Analytical methods for chemical analysis of geologic and other materials, U.S. Geological Survey: U.S. Geological Survey Open-File Report 02-223, available online at http://pubs.usgs.gov/of/2002/ofr-02-0223/OFR-02-0223.pdf. 
Thermo Fisher Scientific, 2006, NITON analyzers release notes for XL3 test stand quick reference guide: Billerica, Mass., NITON Analyzers Headquarters, 4 p.

Thermo Fisher Scientific, 2007, NITON XL3p 600 analyzer user's guide, version 6.0: Billerica, Mass., NITON Analyzers Headquarters, 166 p.

U.S. Geological Survey, 2006, Guidelines for ensuring the quality of information disseminated to the public: U.S. Geological Survey Web site, accessed on February 6, 2009, at http://www.usgs.gov/info_qual/.

Volgelman, J.E., Howard, S.M.,Yang, L., Larson, C.R., Wylie, B.K., and Van Driel, N., 2001, Completion of the 1990s National Land Cover Data Set for the conterminous United States from Landsat Thematic Mapper data and ancillary data sources: Photogrammetric Engineering and Remote Sensing, v. 67, no. 6, p. 650-662. 


\section{Appendix 1. Acronyms and Abbreviations}

\begin{tabular}{|c|c|}
\hline AES & atomic emission spectromtery \\
\hline ANL & Argonne National Laboratory \\
\hline ANSI & American National Standards Institute \\
\hline ASD & Analytical Spectral Devices, Inc. \\
\hline ASQC & American Society for Quality Control \\
\hline AVIRIS & Airborne Visible/Infrared Imaging Meter Spectrometer \\
\hline CAPIARCHER & $\begin{array}{l}\text { Civil Air Patrol Airborne Real-Time Cueing Hyperspatial Enhanced } \\
\text { Reconnaissance }\end{array}$ \\
\hline CERCLA & Comprehensive Environmental Response, Compensation and Liability Act \\
\hline CHRIS & Compact High Resolution Imaging Spectrometer \\
\hline DOE & U.S. Department of Energy \\
\hline DOQQ & digital orthophoto quarter quadrangle \\
\hline DQO & Data quality objective \\
\hline DVD & digital video disk \\
\hline EDXRF & energy dispersive $\mathrm{x}$-ray fluorescence \\
\hline EGSC & Eastern Geographic Science Center \\
\hline EMS & electromagnetic spectrum \\
\hline EPA & United States Environmental Protection Agency \\
\hline ERT & Environmental Response Team \\
\hline ESA & European Space Agency \\
\hline FGDC & Federal Geographic Data Committee \\
\hline FPXRF & field portable x-ray fluorescence \\
\hline GAM & geographic analysis and monitoring \\
\hline GIO & Geospatial Information Office \\
\hline GIS & geographic information system \\
\hline HRS & hyperspectral remote sensing \\
\hline HSI & hyperspectral imagery \\
\hline ICP & inductively coupled plasma \\
\hline LRS & Land Remote Sensing (LRS) Program \\
\hline MF & matched filter \\
\hline MSDS & material safety data sheets \\
\hline MTMF & mixture-tuned matched filter \\
\hline NASA & National Aeronautics and Space Administration \\
\hline NIST & National Institute of Standards and Technology \\
\hline NPL & National Priorities List \\
\hline NSDI & National Spatial Data Infrastructure \\
\hline OIG & Office of Inspector General \\
\hline OMB & Office of Management and Budget \\
\hline PLS & partial least squares \\
\hline QA & quality assurance \\
\hline QAPP & Quality Assurance Project Plan \\
\hline QC & quality control \\
\hline RS & remote sensing \\
\hline SARA & Superfund Amendments and Reauthorization Act \\
\hline
\end{tabular}




$\begin{array}{ll}\text { SLR } & \text { stepwise linear regression } \\ \text { SOP } & \text { standard operating procedure } \\ \text { SRM } & \text { standard reference material } \\ \text { USDOI } & \text { United States Department of the Interior } \\ \text { USGS } & \text { U.S. Geological Survey } \\ \text { VI } & \text { vegetation indices } \\ \text { VISINIR } & \text { visible/near infared } \\ \text { VOC } & \text { volatile organic compound } \\ \text { WR } & \text { white reference } \\ \text { XRF } & \text { X-ray fluorescence }\end{array}$

